\title{
Conceptual design and operation testing of military movable noiseless power supplier (MNPS)*
}

\author{
Seunghyun Lee** $\cdot$ Ikjun Choi*** $\cdot$ Seunghyun Kim****
}

\begin{abstract}
This study verifies the concept and test of the MNPS owing to the increase in advanced weapon systems used in the Korean defense field. MNPS used solar power to eliminate noise, a risk factor of the existing power supply systems, and it was designed in a size that can be mounted on a small tactical vehicle in various battlefield situations. When sunlight is used as a power supplier, in case there is no light, its use is limited; therefore, it can be used after charging through an energy storage device. In addition, it was designed considering scalability to increase the amount of electricity generated through the solar panel or increase the storage capacity. Finally, the power characteristics were analyzed through a test to determine if the output was constant, and through this, it was possible to confirm its feasibility of use for military purposes.
\end{abstract}

Keywords : military power supplier, movable noiseless power supplier, sunlight generation, movable and noiseless vehicle

* Following are results of a study on the "Leaders in INdustry-university Cooperation+" Project, supported by the Ministry of Education and National Research Foundation of Korea.

** (First Author) Woosuk University, Department of Military Technology, Professor, leesh@woosuk.ac.kr, https://orcid.org/0000-0002$5502-585 X$

*** (Co-Author) RED Inc., Senior manager, sales@redsolution.co

**** (Corresponding Author) Woosuk University, Department of Military Technology, Professor, majorkim99@woosuk.ac.kr 


\section{I. 서론}

급속한 과학기술의 발전, 특히 4차 산업혁명의 영향으로 국방분야에서도 이를 적용한 무기체계 의 개발 및 도입이 급속도로 이루어지고 있다. 이에 따라 미래의 전장에서는 통신장비 및 전자장비 의 중요성이 더욱 증대될 것으로 보이며, 이러한 장비들은 자동화, 첨단화를 구현하기 위하여 에너 지원인 전기에 대한 수요가 증가할 것이며, 아울러 그 중요성도 매우 증가할 것이다. 전장에서의 안정적인 이동 및 휴대용 전원의 보급 가능 여부는 이제 전쟁의 승패를 좌우할 수 있는 결정적인 요소가 될 것이며, 군의 전투 준비태세를 측정하는 하나의 지표로도 적용할 수가 있을 것이다.

우리 군은 장비에 대한 이동 및 휴대용 전력 공급원으로서 주로 상용전력과 발전기를 사용하고 있으며, 이 외에 전지를 활용하여 전력을 공급하는 수단으로 활용되고 있다.1) 이러한 자료들을 기 반으로 추산해 볼 때 이중 비상전력으로 사용되는 발전기와 전지에 투입되는 예산은 연간 약 540억 원으로 추정해 볼 수 있을 정도이며, 이는 우리 군의 국방예산을 고려 시 무시할 수 없는 엄청난 금액이며, 향후, 무인화, $\mathrm{AI}$ 기술이 더욱 많이 도입될 경우 그 금액은 더욱 커질 것으로 예상된다. 또한, 우리 정부는 최근 지구 온난화에 대비한 국제사회 및 정부 정책의 한 기조로 온실가스 감축 과 환경규제에 대응하기 위하여 전기차(EV : Electric Vehicle)의 개발과 보급을 활발하게 추진하고 있다(Kim, Lee, \& Lee, 2017; Kwon \& Kim, 2017).

본 연구에서 제안하는 군사용 이동형 무소음 전원 공급체계(MNPS : Movable Noiseless Power Supplier)는 이러한 정부의 정책에 대비해 향후 증가될 군사용 전기장치 및 전기차에 대비하기 위 해 착안하였다. 아울러, 현재 사용하는 비상전력용 발전기는 동력원이 디젤/가솔린 기관을 사용함 에 있어서 소음과 주기적인 연료 보급이 수반되어야 하는데(Pang \& Kim, 2015), 이러한 제한사항 을 극복하기 위하여 MNPS는 태양광을 활용하여 군에서 보유한 기존 전력 공급체계의 문제점을 해결하기 위한 군사용 이동형 무소음 전원공급체계 개발을 제안한다.

\section{ㅍ. 연구방법}

\section{1 군사용 MNPS의 구성}

\subsection{1 기존 전원발생장비와 MNPS의 차별성}

MNPS와 비교해야 할 기존 전원발생장치는 기존 군사용으로 사용하고 있는 가솔린/디젤 기관을 사용하는 이동형 전원발생체계와 MNPS와 동일한 방식으로 전원을 발생하는 고정형 태양광 전원 발생체계로 구분할 수 있다.

1) SMI(2014). 발전기 적정 수명기준 연구. 국방부, http://www.smi.re.kr/reactive/firstpub/read.jsp?reqPageNo=3\&no=245 
첫째, 기존에 군에서 사용하고 있는 전원발생장치는 전동기, 엔진 또는 각종 터빈 등의 원동기에 서 발생하는 힘, 즉 기계 에너지를 전기에너지로 변환하는 장치를 말하며, 속도의 변화나 부하의 특성을 이용하여 독립적이면서 안정적으로 전기를 발생시킨다. 하지만, 원동기에서 발생하는 기계 적인 에너지를 이용하다 보니 원동기의 소음이 수반될 수밖에 없는 상황이며(Kim, Kim, Yun, \& Shin, 2020), 전원발생장치는 주로 사용되는 분야는 통신장비, 레이더 장비, 시설등화(施設燈火22)를 위해 사용되고 있는 점을 고려한다면, 원동기로 인해 발생되는 소음이 주요 시설의 위치를 노출 시 키는 결과로 이어질 수 있다. 또한, 원동기의 힘을 발생시키기 위해서는 가솔린, 디젤, 가스 등과 같은 연료를 지속적으로 소모함으로써 전원발생장치의 운영유지비도 지속적으로 발생될 수 있는 제한사항을 갖고 있다. 둘째, 고정형 태양광 전원발생장치는 최근 우리 정부에서 지구 온난화에 대 비한 국제사회 및 정부 정책의 한 기조로 온실가스 감축과 환경규제에 대응하기 매우 많은 곳에 설치 운영되고 있다. 하지만, 군사용으로 사용하기 위해서는 일부 후방부대에서나 가능한 부분이 며, 부대이동이 잦은 전방부대 및 지형적 특성으로 시설공사가 제한되는 부대에서는 이러한 고정형 전원발생장치를 설치하기에 제한된다(e.g., Kim, Hong, Jung, \& Choi, 2016).

따라서 이 연구에서는 제기된 소음, 지속적인 연료 보급, 부대이동 및 지형적 특성을 극복할 수 있는 군사용 MNPS를 제안한다. 여기서 MNPS는 태양광을 이용하여 에너지저장장치에 저장하고, 저장장치와 태양광전원발생장치에서 생성된 전력을 필요 장비나 요소에 전력을 공급해 주는 장비 이다.

\subsubsection{MNPS의 구성}

$\mathrm{MNPA}$ 는 <Figure $1>$ 과 같이, 태양광전원발생장치, 에너지저장장치, 감시제어장치, 충전장치, 외 관 조립체로 구성되며 이동하여 운영할 수 있는 장점을 갖고 있다. 태양광전원발생장치는 태양광으 로부터 발생된 에너지를 전력변환장치를 통해 에너지저장장치 및 충전기로 공급한다( $\mathrm{An}, \mathrm{Kim}$,

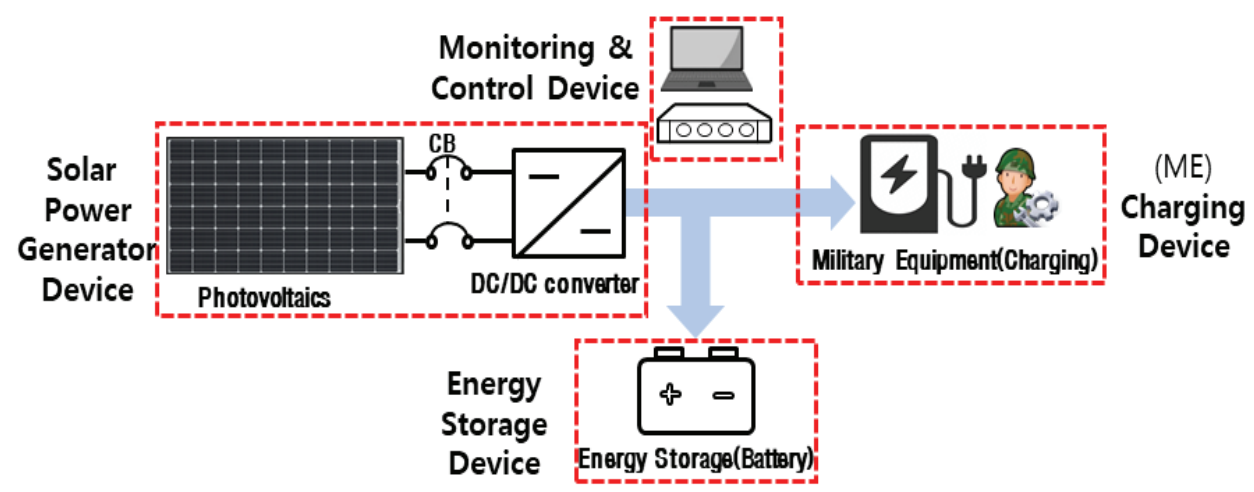

$<$ Figure 1> Detailed configuration of MNPS

2) 시설등화(施設燈火) : 도구, 장치 따위를 설비하여 등을 밝히는 일 
Won, Kwon, \& Kim, 2012). 에너지저장장치는 리틈이온 배터리로 되어 있어, 운용모드에 따라 에 너지를 비축하거나, 충전기를 통해 전력을 공급한다. 감시제어장치에서는 전류, 전압, 충전량(SOC : State of Charge) 및 온도를 측정하고, 차단기 제어 등 모드전환을 수행한다.

특히, 군사용으로 운용하고 이동이 가능하기 위해서 MNPS의 사이즈를 군사용 표준차량에 탑재 될 수 있는 크기로 개발해야 전시 이동을 위한 차량 탑재가 가능하다. 군사용 표준차량은 $1 / 4$ 톤, 1 $1 / 4$ 톤, $21 / 2$ 톤, 5 톤, 15 톤 그리고 소형 전술차량이다.3) 이 중 $1 / 4$ 톤의 경우, 현재 상용차를 도입해 운용하고 있으며, 가장 작은 크기의 군사용 표준차량이다. 소형전술차량의 형상과 탑재공간의 제원 은 <Figure 2>와 같으며, 군사용으로 MNPS를 운용하기 위해서는 탑재공간에 적재될 수 있는 크 기로 개발되어야 한다. 특히, 소형전술차량은 전술용도로 운용하기 위해 개발된 차량으로 유사 시 부대이동 등 전술작전에 투입되어야 할 차량이므로 MNPS를 군사용으로 운용하기 위해서는 소형 전술차량에 탑재될 수 있도록 하는 것이 타당하다(Kim, Lee, Lee, \& Jeong, 2021).

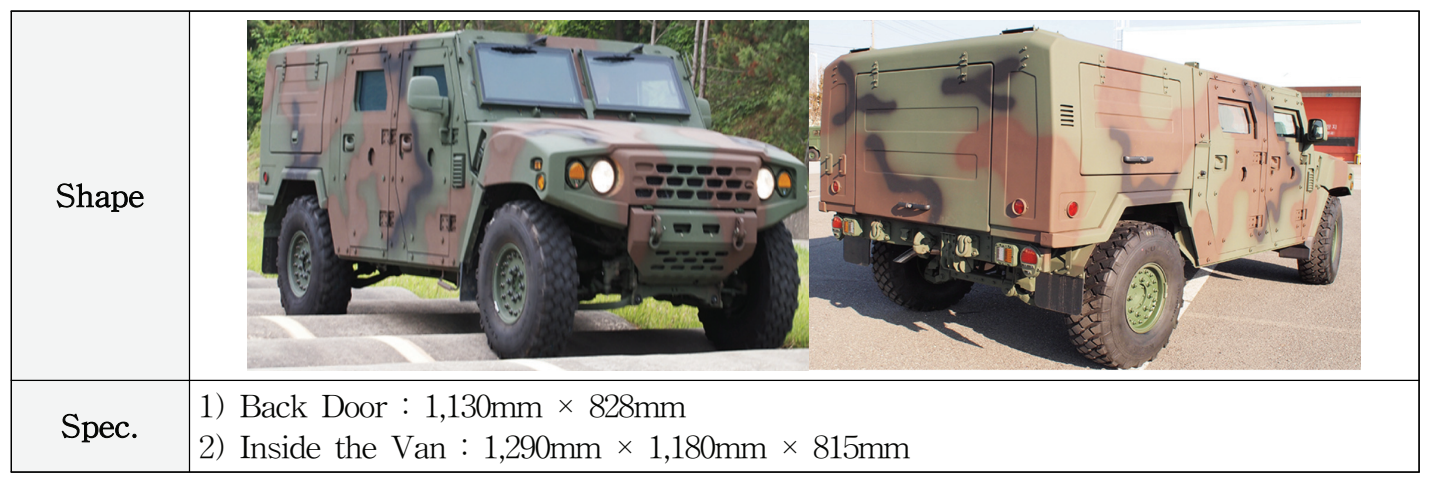

$<$ Figure 2> Shape and mounting space specification of small tactical vehicle

<Figure 2>에서와 같이 소형전술차량의 후방밴에 탐재할 것을 고려 시, 밴 내부는 1,290 (좌 우) $\times 1,180$ (전후) $\times 815$ (높이)로 후방도어 사이즈보다 MNPS의 사이즈가 크면 밴 내부에서 인출이 불 가하다. 이를 고려하여 좌우 사이즈는 최대 1,130 (좌우) $\times 1,180$ (전후) $\times 815$ (높이)를 충족하도록 $<$ Figure $3>$ 과 같이 모델링하였다.

3) http://special.kia.com : 1/4톤 $(4,930 \mathrm{~mm} \times 1,915 \mathrm{~mm} \times 1,810 \mathrm{~mm}), 1 \quad 1 / 4$ 톤 $(5,460 \mathrm{~mm} \times 2,180 \mathrm{~mm} \times 2,450 \mathrm{~mm}), 2 \quad 1 / 2$ 톤 $(6,800 \mathrm{~mm} \times$ $2,500 \mathrm{~mm} \times 2,900 \mathrm{~mm}), 5$ 톤 $(7,790 \mathrm{~mm} \times 2,500 \mathrm{~mm} \times 3,000 \mathrm{~mm})$, 소형전술차량 $(4,900 \mathrm{~mm} \times 2,195 \mathrm{~mm} \times 1,980 \mathrm{~mm})$ 

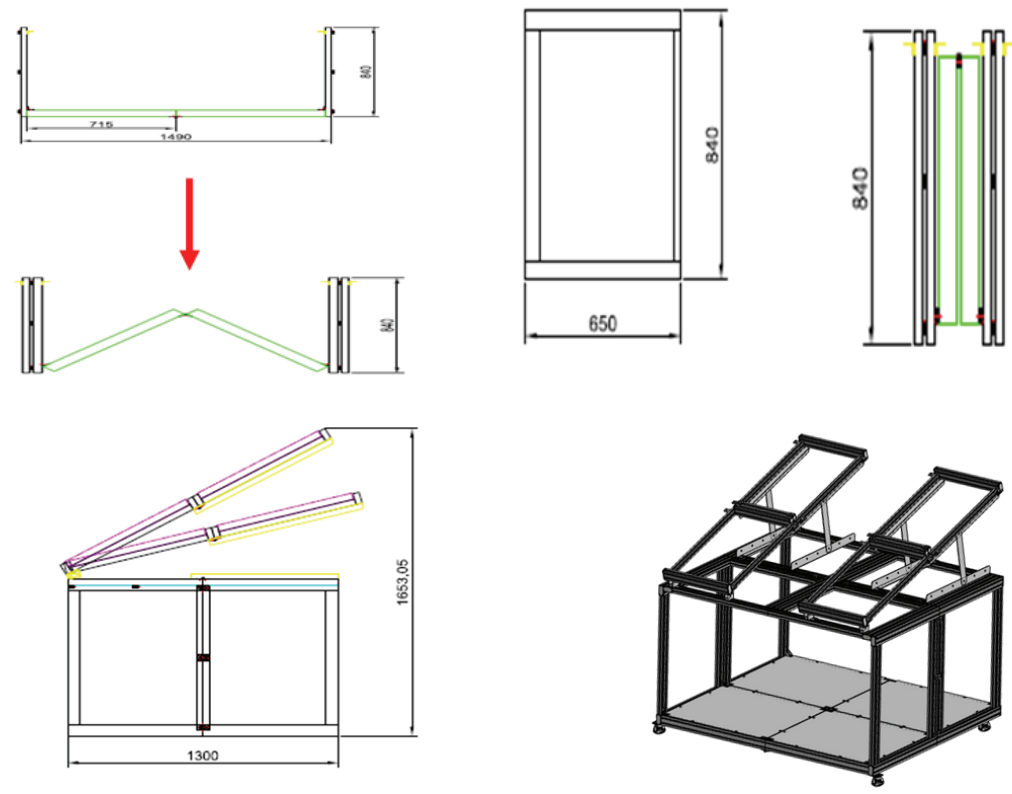

$<$ Figure 3> External Modeling of MNPS

\section{2 이동형 무소음 전원공급체계의 구현}

\subsection{1 태양광전원발생장치}

태양광전원발생장치는 태양광으로부터 에너지를 수집하기 위한 태양광모듈과 $\mathrm{MPPT}$ (태양광 전 원 컨트롤러; Maximum Power Point Tracking) 제어를 수행하는 직류/직류(DC/DC) 컨버터로 구 성되며, <Figure 4>와 같다. 여기서, 태양광모듈은 STC(standard test condition)에서 2[kW]의 정 격출력이 발생되며, 최대 출력점 $\left(P_{m p}\right)$ 에서의 전압은 $48.63[\mathrm{~V}]$, 전류는 $43.23[\mathrm{~A}]$ 이다. <Figure $1>$ 에 서 $\mathrm{DC} / \mathrm{DC}$ 컨버터가 태양광모듈을 연결하여, $\mathrm{MPPT}$ 를 통해 발생된 전력을 에너지저장장치의 배터 리에 충전하거나, 각종 군사용 장비 $(\mathrm{ME})$ 에 공급할 수 있도록 한다. $\mathrm{DC} / \mathrm{DC}$ 컨버터와 태양광모듈의 사양과 전기적 특성은 <Table 1 >과 같다.

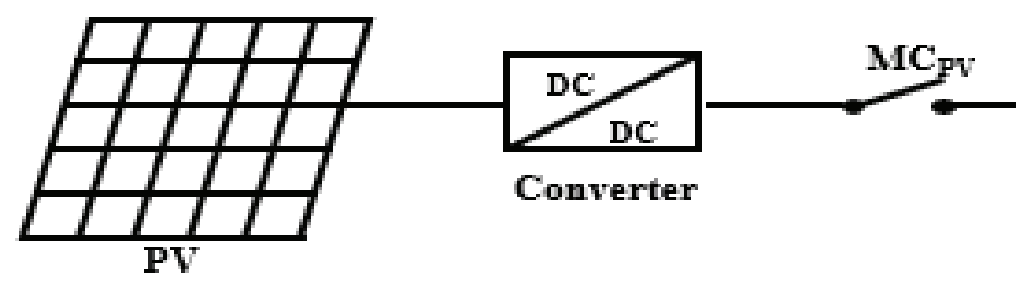

$<$ Figure 4> Solar Power Generator Configuration Diagram of MNPS 
$<$ Table 1> Specifications of Solar Power Generator

\begin{tabular}{c|c|c}
\hline Item & \multicolumn{2}{|c}{ Spec. } \\
\hline \hline \multirow{4}{*}{ Solar Module } & Rated Power & $400[\mathrm{~W}] \times 4$ pannel \\
\cline { 2 - 3 } & Voltage MAX.(Vmp) & $48.63[\mathrm{~V}]$ \\
\cline { 2 - 3 } & Current MAX.(Imp) & $43.28[\mathrm{~A}]$ \\
\cline { 2 - 3 } & Voltage of Open Circuit(Voc) & $59.01[\mathrm{~V}]$ \\
\cline { 2 - 3 } & short circuit current(Isc) & $43.48[\mathrm{~A}]$ \\
\hline \multirow{2}{*}{ DC/DC Converter } & Rated Power & $5[\mathrm{~kW}]$ \\
\cline { 2 - 3 } & DC Input Voltage & $51.5[\mathrm{~V}]$ \\
\hline
\end{tabular}

\subsection{2. 에너지저장장치}

$\mathrm{MNPS}$ 의 에너지저장부는 태양광전원발생장치와 $\mathrm{AC}$ 전원 계통(상용전력)으로부터 에너지를 저 장하는 배터리팩과 이를 감시하고 안전하게 제어하기 위한 배터리 관리체계(BMS : battery management system)로 구성한다(Figure 5). 배터리팩은 3.3[kWh]급 리튬이온 배터리 4개를 직렬 로 연결하여 1 개의 세트를 구성하고, 이러한 세트를 다시 병렬로 연결하여 모듈화하여 총

$<$ Table 2> Specifications of Energy Storage

\begin{tabular}{c|c|c}
\hline Item & \multicolumn{2}{|c}{ Spec. } \\
\hline \hline \multirow{2}{*}{$\begin{array}{c}\text { Energy Storage } \\
\text { (Li-ion battery) }\end{array}$} & Nominal Voltage & $168 \sim 235.2[\mathrm{~V}]$ \\
\cline { 2 - 3 } & Capacity & $26.4[\mathrm{Ah}]$ \\
\cline { 2 - 3 } & Weight & $28 \mathrm{~kg} * 4 \mathrm{ea}=112 \mathrm{~kg} / \mathrm{set}, 224 \mathrm{~kg} / \mathrm{pack}$ \\
\hline
\end{tabular}

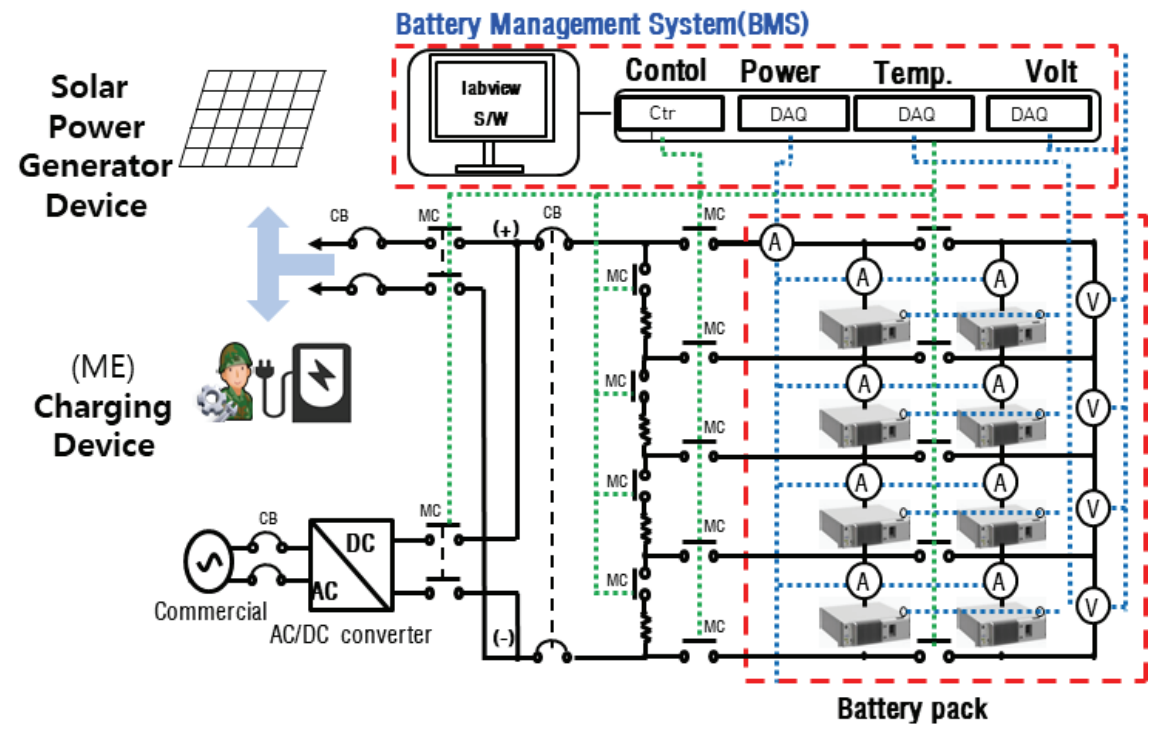

$<$ Figure 5> Energy Storage Device Configuration Diagram of MNPS 
Conceptual design and operation testing of military ... / Seunghyun Lee $\cdot$ Ikjun Choi • Seunghyun Kim 183

26.4[kWh]의 용량을 저장할 수 있도록 팩을 구성하였다(Table 2).

\section{2 .3 충전장치}

$\mathrm{MNPS}$ 의 충전장치는 태양광전원발생장치에서 직접 공급되는 전력, 또는 에너지저장장치의 배터 리로부터 공급되는 전력으로 군사용 장비(ME; Military Equipment)에 전력을 공급 또는 충전하는 역할을 수행한다. 충전장치의 정격용량은 $25[\mathrm{~kW}]$ 급으로 구성하며, 공급/충전 가능한 전압의 범위 는 전기 공급이 필요한 장비에 무관하도록 50 450[V]로 구성하였다.

\section{2 .4 감시제어장치}

$\mathrm{MNPS}$ 의 감시제어장치는 <Figure 5>의 상단 BMS를 말하며, Labview S/W를 이용하여 각 모 듈에 연결된 계측장치로부터 전압, 전류, 온도 등을 측정하여, 배터리를 평가하거나, 셀의 밸런싱 상태를 감시하여 각 셀의 전압을 균등하게 제어한다. 전원공급체계가 군사적으로 운용되기 위해서 는 험준한 산악지역에서 운용될 수 있으며, 숲이나 나무 등으로 인해 MNPS를 운용하는 장소에 음 영이 발생할 가능성이 높다. 따라서 태양광을 이용한 전원공급체계인 MNPS는 음영으로 인해 출력 에 영향을 받을 수 있게 되며, MNPS의 전력으로 운용되어야 할 군사용 장비들은 제 기능을 할 수 없게 될 수도 있어 MNPS의 전압을 일정하게 유지하는 기능이 반드시 필요하다. 또한, MNPS의 운용 중에 에너지저장장치 또는 $\mathrm{ME}$ 측에 이상한 징후가 발생할 경우, 에너지저장장치의 회로를 신속하게 차단하고 경고함으로써 사용자가 적절하게 조치할 수 있도록 한다.

\subsection{MNPS의 운용 개념}

\subsection{1 기본 운용(충전) 개념}

$\mathrm{MNPS}$ 의 운용 방법에는 태양광 전원발생장치나 상용전원에 의해 발생된 전력을 에너지 저장부

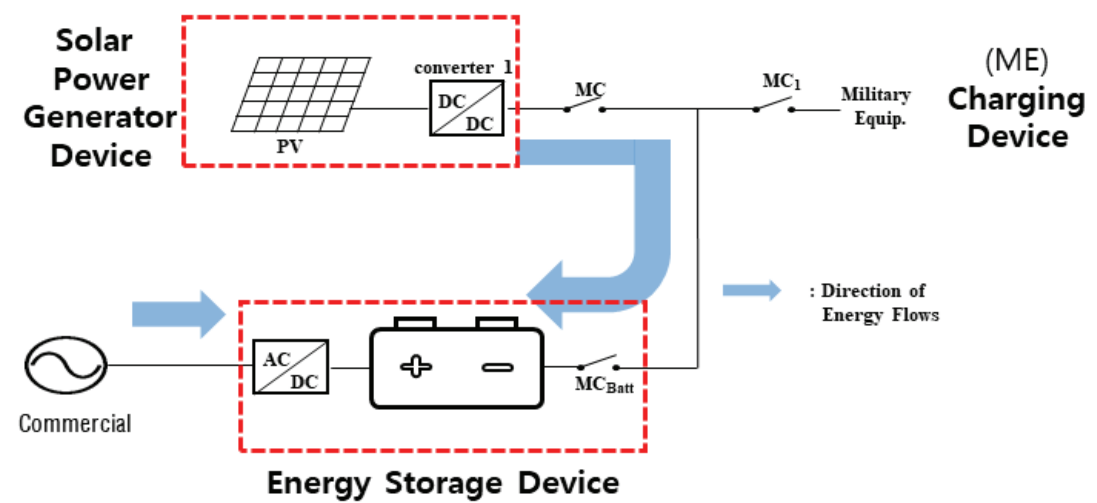

$<$ Figure 6> Conceptual Diagram of Charging Power to the Energy Storage of MNPS 
에 충전하는 충전과 에너지 저장장치로부터 충전기를 통해 외부로 전력을 보내주는 공급으로 나눌 수 있다. 공급에는 “에너지저장장치”에서 단독으로 공급하는 방법과 “태양광 전원발생장치 + 에너 지저장장치” 에서 병렬로 공급하는 방식으로 구분하여 운용할 수 있다. <Figure 6>은 태양광을 이 용하여 전원발생장치에서 발생된 전력, 또는 상용전원을 이용하여 확보된 전력을 에너지저장장치 에 충전하는 개념을 보여준다.

\subsection{2 군사 분야에서의 운용(공급) 개념}

$<$ Figure 7>은 태양광전원발생장치 또는 에너지저장장치로부터 나오는 전력을 외부로 공급하는 개념을 보여준다. 이때, 태양광전원장치와 에너지저장장치의 병렬식 전력 공급은 (1)과 같이 에너지 저장부의 단독공급 방식은 (2)와 같은 경로로 운용하는 방식이다.

(ME)

Charging Device

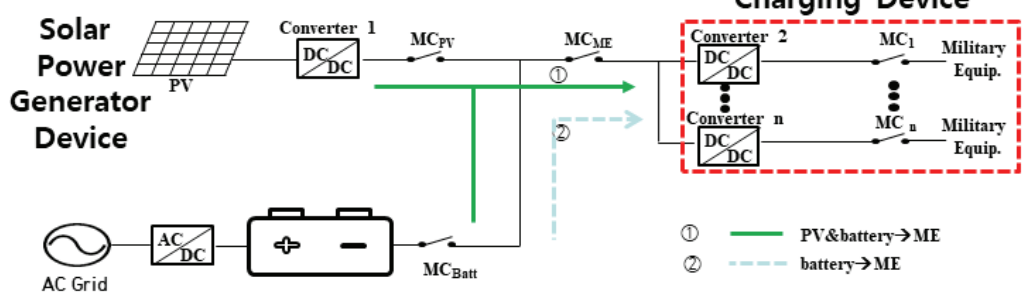

Energy Storage Device

$<$ Figure 7> Supplying Power to External Devices in MNPS

$\mathrm{MNPS}$ 를 이용한 전원 공급을 이용한다면, 주간 및 평시에 전력을 충전 후 비상시 또는 예비전원 이 필요 시 활용할 수 있다. 특히, 태양광 전원발생장치와 에너지저장장치는 필요에 따라 <Figure $8>$ 처럼 확장할 수 있어 대용량 전원이 필요한 경우 태양광모듈을 늘려 충전 시간을 줄이거나, 배터 리를 늘려서 운용 시간을 증대 또는 공급 출력을 향상시키는 형태로 운영개념을 확대할 수 있다.

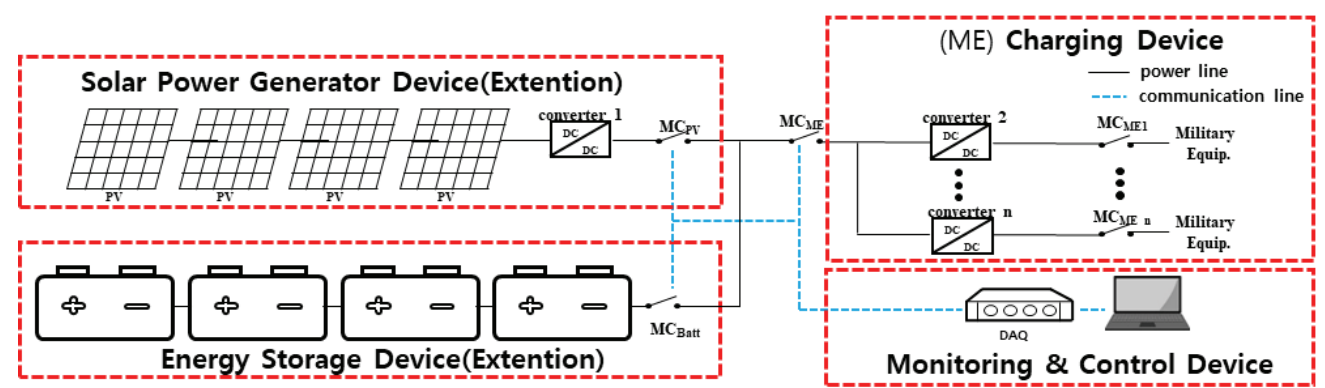

$<$ Figure 8> Extended Operational Concept of MNPS 
Conceptual design and operation testing of military ... / Seunghyun Lee $\cdot$ Ikjun Choi - Seunghyun Kim 185

또한 필요 시에 개별 분리 후 차량 적재/이동이 가능하여 기존의 발전기들과 차이점을 갖게 되 며, 소음이 없고, 연료공급 없이 운용이 가능한 점은 군사적 이용에 크게 기여할 수 있을 것으로 기대되며, 다음과 같은 경우에 그 효과성 및 효율성이 높아질 것이다.

(1) 교통이 불편한 격오지 부대

(2) 무인 레이더 또는 감시장비 운영기지

(3) 기도비닉(企圖秘匿)4)이 요구되는 소규모 임무 수행 시
(4) 부대 이동한 지휘시설의 비상전력 운용 시

(5) 기타 시설 보호가 필요한 통신, 방공시설 등

\subsection{MNPS의 군사작전 지역의 특성을 고려한 운용 시험}

감시제어장치는 군사작전 지역의 특성을 고려하여 태양광전원발생장치가 음영이 발생할 가능성 이 높으며, 음영이 발생되어도 출력에 영향이 발생되지 않고 일정하게 유지될 수 있는 기능을 구현 하였다. 본 연구에서는 음영이 발생됨에 따라 출력이 변동되는 것을 방지할 수 있도록 설정하였으 며, 이 기능이 구현되는지를 시험하였다. 시험에 적용된 시스템은 시험공간에 맞게 정격용량을 $1 / 4$ 로 축소하였으며, 시험에 적용된 체계의 규격은 <Table 3 >과 같다.

$<$ Table 3> Specifications of MNPS Testing Model

\begin{tabular}{c|c|c}
\hline \multirow{4}{*}{ Item } & \multicolumn{2}{|c}{ Standard } \\
\hline \hline \multirow{4}{*}{ Solar Module } & Rated Power & $400[\mathrm{~W}]$ \\
\cline { 2 - 3 } & Voltage MAX.(Vmp) & $18.1[\mathrm{~V}]$ \\
\cline { 2 - 3 } & Current MAX.(Imp) & $5.53[\mathrm{~A}]$ \\
\cline { 2 - 3 } & Voltage of Open Circuit(Voc) & $22.26[\mathrm{~V}]$ \\
\cline { 2 - 3 } & short circuit current(Isc) & $5.86[\mathrm{~A}]$ \\
\hline \multirow{2}{*}{ DC/DC Convertor } & Rated Power & $400[\mathrm{~W}]$ \\
\cline { 2 - 3 } & DC Input Voltage & $22 \sim 60[\mathrm{~V}]$ \\
\hline \multirow{2}{*}{ Battery } & Nominal Voltage & $37[\mathrm{~V}]$ \\
\cline { 2 - 3 } & Capacity & $10.4[\mathrm{Ah}]$ \\
\hline
\end{tabular}

\subsubsection{MNPS의 음영 발생 시 운용특성 분석}

상기에 제시한 시험조건을 토대로 공급 장치인 태양광전원 측 전압 및 출력특성을 나타내면 $<$ Figure 9>와 <Figure 10>과 같다. 음영이 발생되지 않은 경우는 (1)과 같고, 스트링 전압은 $37.2[\mathrm{~V}]$, 출력은 364.8[W]이다. 또한, 음영이 태양광전원 면적의 $50 \%$ 가 발생했을 경우는 (2)와 같다. 태양광의 스트링 전압 및 출력은 음영으로 인해 순간적으로 감소 되지만, 회로변경에 의해 음영이

4) 기도비닉(쇼圖秘㕆) : 은밀한 활동, 비밀스럽거나 숨겨야 하는 상황 
없는 부분의 모듈끼리 스트링을 구성하게 되므로, 스트링의 전압 및 출력은 각각 35.8[V], 183.4[W] 로 유지된다. 한편, 태양광전원 면적의 $75 \%$ 음영이 발생한 경우는 (3)과 같고, 제어장치에 의해 리 튬이온전지가 투입되어 전압 및 출력은 순간적으로 감소 되지만, 전압은 $36.1[\mathrm{~V}]$, 출력은 리튬이온 전지의 방전에 의해 $188.1[\mathrm{~W}]$ 로 유지된다. 따라서, 본 연구에서 제시한 감시제어장치의 스마트 제 어 기능은 태양광전원장치가 음영발생 하더라도 출력이 저하되지 않아 공급 장치의 유용성을 확인 할 수 있었다.

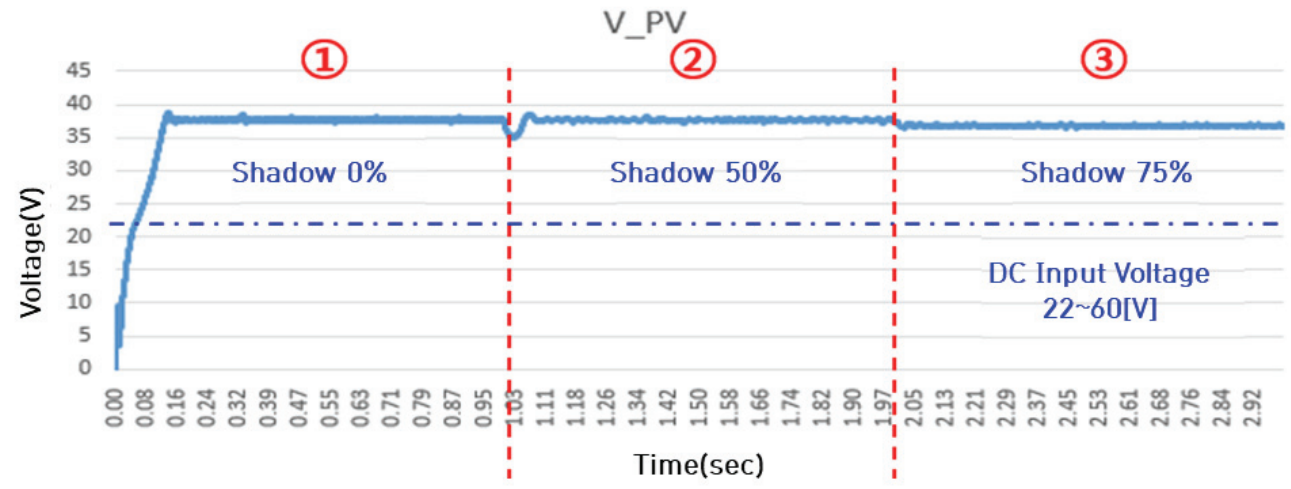

$<$ Figure 9> Voltage in Shadow Situation of MNPS

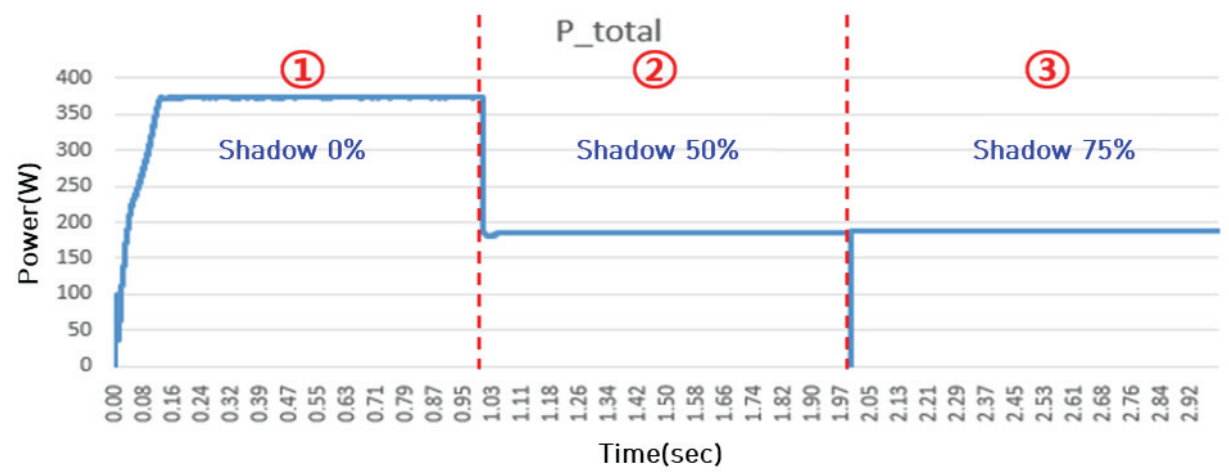

$<$ Figure 10> Power characteristics in Shadow Situation of MNPS 


\section{III. 결론 및 논의사항}

향후 군에서는 학령인구 감소로 인한 병력 감소와 4 차 산업혁명으로 과학기술의 발달로 인한 각 종 첨단 무기체계가 더욱 많이 도입될 것이다. 이에 본 연구에서는 미래 전장을 대비하기 위한 군 사용 이동형 무소음 전원공급체계인 MNPS를 설계 및 제작하였으며, 설계된 MNPS의 형상 및 운 용의 타성성을 확인하기 위해 운용시험을 수행하였다. 그 결과는 다음과 같다.

첫째, 본 연구에서 설계한 MNPS는 운용시험 결과, 안정적인 전력 생산을 확인하였으며, 군사작 전 지역의 특성을 고려한 음영 발생 시에도 안정적인 전원공급체계로서 타당성을 확인하였다. 특 히, 이동형 무소음 전원공급체계로 개발함에 따라 기존의 전원공급체계에서 제기되었던 소음과 고 정형이라는 문제를 동시에 해결할 수 있었다.

둘째, 군사적 운용개념에 대해 검토한 바와 같이 MNPS의 운용개념을 설정하고 확장성을 고려한다 면 향후에 본 연구의 결과가 미래 전장을 대비하기 위한 국방 분야에서 유용하게 활용될 것이다. 예를 들어, 이동식이면서 추가적인 연료공급 없이 무소음으로 사용할 수 있다는 점에서 군사적인 활용가치 가 매우 높다고 볼 수 있다. 특히, 현재 운용 중인 전력발생장치들은 용량별 규격이 상이하여 다품종을 관리함에 따른 운영유지에 어려움이 많으나, 군사용 MNPS는 확장성이 높아 도입시 용량의 크기에 상 관없이 운용이 가능할 수 있어 전술적인 측면 이외에 군수지원 측면에서도 기여할 수 있을 것이다.

셋째, 개념설계 시 확장성에 대한 검토결과, 본 연구 단계에서 실제 실험을 통해 확인하지는 못 하였지만, 전기의 운용 특성상 충분히 구현될 수 있을 것이다. 하지만 이번 연구를 통해 군사적으로 활용 가능한 이동형 무소음 전원공급체계에 대한 개념 설계와 운용시험을 통해 그 실용적 가치를 증명한 것에 큰 의미를 둘 수 있다. 본 연구는 짧은 연구기간에 실험실 시험평가와 승용차 탑재 평 가 수준에서 진행되어 보다 실제 야전 환경5)을 반영한(high-fidelity) 시험을 진행하지 못한 한계점 을 갖고 있다. 그래서 추후 연구는 군사적 운영에 적합한 실제 환경에서 실험을 통해 제품의 견고 성 등을 강화하는 등 추가 연구가 진행된다면 보다 의미있는 결과를 얻을 수 있을 것이다.

\section{Acknowledgements}

We would like to thank Editage (www.editage.co.kr) for English language editing.

\section{Declaration of Conflicting Interests}

The author(s) declared no potential conflicts of interest with respect to the research, authorship, and/or publication of this article.

5) 실제 야전 환경 : 승용차가 아닌 소형전술차량에 탑재 운용(강한 진동)하고, 계절적 특성, 진동특성, 강우강설 등의 야전 환경 


\section{Reference}

An, G. M., Kim, C. M., Won, S. Y., Kwon, J. W., \& Kim, H. S. (2012). Using a stand-alone PV systems in remote military research on the design of power facilities. Proceedings of Conference of the Institute of Control, Robotics and Systems, 731-736. https://www.dbpia. co.kr/pdf/pdfView.do?nodeId=NODE02226826\&mark=0\&useDate=\&ipRange=N\&accessgl= Y\&language=ko_KR

Kim, M. C., Lee, H. S., Lee, I. S., \& Jeong, M. G. (2021). A Study on the Current Status and Effect Analysis of Military Standard Vehicle Commercialization. Research of Regional Industry, 44(3), 327-343. https://www.kci.go.kr/kciportal/ci/sereArticleSearch/ciSere ArtiView.kci?sereArticleSearchBean.artiId=ART002753622

Kim, N. H., Hong, J. T., Jung, S. Y., \& Choi, K. H. (2016). Study of The Mobile ESS For Military Camp. Proceedings of Conference of the Korean Institute of Power Electronics, 171-172. https://scienceon.kisti.re.kr/srch/selectPORSrchArticle.do?cn=NPAP12690767

Kim, S. J., Kim, S. G., Yun, S. H., \& Shin, C. H. (2020). A study on the way to improve abnormal noise by applying vehicle fitting type generator. Journal of the Korea AcademiaIndustrial cooperation Society, 21(6), 266-274. https://doi.org/10.5762/ KAIS.2020.21.6.266

Kim, S. Y., Lee, S. L., \& Lee, J. W. (2017). Analyzing the Effect of Electric Vehicle Supply on Greenhouse Gas Emissions in 2030. Journal of Environmental Policy and Administration, 25(4), https://doi.org/10.15301/jepa.2017.25.4.39

Kwon, P. S., \& Kim, S. J. (2017). Scenario Analysis for the Achievement of the 2030 National Greenhouse Gas Reduction Goal in the Korean Electricity Sector. Journal of Environmental Policy and Administration, 25(2), 129-163. https://doi.org/10.15301/jepa.2017.25.2.129

Pang, S. K., \& Kim, J. H. (2015). A Design Optimization on Coupling Joint between Exhaust Chimney of Electricity Generator and Electromagnetic Pulse (EMP) Shield. Journal of Energy Engineering, 24(4), 159-165. https://doi.org/10.5855/ENERGY.2015.24.4.159 
IDAP 광운대항교 방위사ㅇㅓㅓ연국소

2021, Vol. 4, No. 3, 177-189.

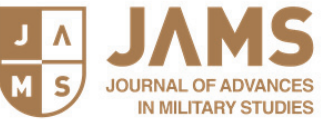

https://doi.org/10.37944/jams.v4i3.131

\title{
군사용 이동형 무소음 전원공급체계(MNPS)의 개념설계 및 운용시험*
}

\author{
이승현** · 최익준*** · 김승현****
}

\section{국문초록}

본 연구에서는 국방분야에 사용되는 첨단무기체계의 증가로 추가적인 전력의 공급에 대한 방안을 마 련하고자, 군사용 이동형 무소음 전원공급체계(MNPS)에 대한 개념과 시험을 통해 실용성음 검증하는 데 그 목적을 두고 있다. MNPS는 기존의 전원공급체계들이 갖고 있는 위험요소인 소음을 제거하기 위하여 태양광을 사용하였으며, 다양한 전장상황에 대응하기 위해 이동할 수 있도록 소형전출사량에 탑재 가능한 크기로 설계하였다. 전원발생에 있어서 태양광을 사용할 경우 빛이 없을 경우 사용이 제 한되는 점을 대비하여 에너지 저장장치를 통해 충전 후 사용할 수 있도록 하였다. 또한 태양광 패널을 통한 전력량을 늘리거나 저장용량을 늘릴 수 있도록 확장성을 고려하여 설계하였다. 마지막으로 실제 군사용으로 사용시 산악 지형으로 인한 음영이 발생될 수 있는데, 이러한 경우에 출력이 일정한지 테스 트를 통해 전력의 특성을 분석하였으며, 이를 통해 군사용으로서의 활용 가능성을 확인할 수 있었다.

주제어 : 군사용 전원공급체계, 이동형 무소음 전원공급체계, 태양광 발전, 이동형/무소음 차량

* 본 과제(결과물)는 교육부와 한국연구재단의 재원으로 지원을 받아 수행된 사회맞춤형 산학협력 선도대학(UNC+) 육성사업의 연구결과입니다.

** (제1저자) 우석대학교 군사기술학과 교수, leesh@woosuk.ac.kr, https://orcid.org/0000-0002-5502-585X

*** (공동저자) (주RED Senior Manager, sales@redsolution.co

**** (교신저자) 우석대학교 군사기술학과 교수, majorkim99@woosuk.ac.kr 
